Marc d'Avoine

Arzt und Praxis in Krise und Insolvenz 


\section{RWS-Skript 372}




\title{
Arzt und Praxis in Krise und Insolvenz
}

\author{
2., neu bearbeitete Auflage \\ 2016
}

von

Rechtsanwalt Dr. Marc d'Avoine,

Fachanwalt für Steuerrecht und Handels- und Gesellschaftsrecht, Ratingen

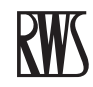

RWS Verlag Kommunikationsforum GmbH · Köln 
Die Deutsche Nationalbibliothek verzeichnet diese Publikation in der Deutschen Nationalbibliografie; detaillierte bibliografische Daten sind im Internet über http://dnb.d-nb.de abrufbar.

\section{(C) 2016 RWS Verlag Kommunikationsforum GmbH}

Postfach 2701 25, 50508 Köln

E-Mail: info@rws-verlag.de, Internet: http://www.rws-verlag.de

Das vorliegende Werk ist in all seinen Teilen urheberrechtlich geschützt. Alle Rechte vorbehalten, insbesondere das Recht der Übersetzung, des Vortrags, der Reproduktion, der Vervielfältigung auf fotomechanischem oder anderen Wegen und der Speicherung in elektronischen Medien.

Satz und Datenverarbeitung: SEUME Publishing Services GmbH, Erfurt Druck und Verarbeitung: CPI books GmbH, Leck 